\title{
A VARIABILIDADE NOS CONSUMOS DE ÁGUA DAS FAMÍLIAS DOS ESTUDANTES E O AVALE-EB
}

\author{
Eliene Costa dos Santos Amorim, Irene Maurício Cazorla e Elaine Costa dos Santos \\ Secretaria de Educação do Estado da Bahia, Brasil \\ Universidade Estadual de Santa Cruz, Brasil \\ Universidade Federal da Bahia, Brasil \\ icazorla@uol.com.br
}

O objetivo com este artigo é apresentar as potencialidades do Ambiente Virtual de Apoio ao Letramento Estatístico (AVALE-EB) para os trabalhos no contexto da Educação Básica envolvendo a interpretação de dados e as formas de representá-los graficamente ou através de medidas estatísticas. O AVALE-EB é um ambiente de aprendizagem virtual, gratuito, que disponibiliza Sequências de Ensino (SE) para trabalhar tópicos de Probabilidade e Estatística. A SE Planeta Água é uma das presentes neste ambiente e, da forma como está estruturada, permite a investigação da variabilidade nos consumos de água mensais das familias dos estudantes, ao longo de um ano e, ao mesmo tempo, estabelecer conjecturas sobre os possíveis fatores que contribuem para os gastos apresentados. Em aplicações dessa SE estudantes demonstraram-se motivados e envolvidos, deram significados aos conceitos, conseguindo fazer leituras $e$ interpretações de gráficos, e chegaram à conclusões com base nos dados e medidas estatísticas.

\section{INTRODUÇÃO E PROBLEMÁTICA}

As reflexões em torno de questões referentes à necessidade de compreensão de conceitos estatísticos, por cidadãos em geral que precisam tomar decisões com base em informações disponibilizadas nos mais variados meios de comunicação, tem nos sensibilizado e, ao mesmo tempo, conduzido a elaborar formas de contribuir com o ensino de conteúdos relacionados, para que, ainda no contexto da Educação Básica, estudantes sejam preparados para avaliar e analisar criticamente mensagens que contenham esses teores, conforme as ideias sobre letramento estatístico propostas por Gal (2002).

Por outro lado, a necessidade de preservação do meio ambiente e dos recursos naturais disponíveis tem sido alvo de muitas discussões que parecem convergir para a preocupação relacionada à sua escassez e disponibilidade à gerações futuras. Nesse trabalho o enfoque é dado a um recurso em especial: a água, devido à sua grande importância no que diz respeito à perpetuação da espécie humana e pelos desafios que deveremos enfrentar até aprendermos a consumi-la de forma consciente e sem desperdícios.

Pelo exposto até o momento, procuramos reunir argumentações que respaldassem a opção em apresentar aqui, o que consideramos corresponder à síntese do relato de um trabalho que vem sendo desenvolvido em sala de aula, nas turmas da Educação Básica e perpassa por um roteiro que solicita o conhecimento de conceitos básicos da estatística, que são sugeridos pelos Parâmetros Curriculares Nacionais (BRASIL; 1997, 1998, 2002) para o nível de estudos em questão e, por sua vez, são utilizados como ferramentas para desenvolvimento de estratégias de consumo consciente desse líquido tão precioso.

O contexto em que as atividades são implementadas é o da Sequência de Ensino (SE) denominada Planeta Água disponível no Ambiente Virtual de Apoio ao Letramento Estatístico (AVALE-EB). O AVALE-EB é um ambiente de aprendizagem resultante do trabalho conjunto de um grupo de pesquisadores que preocupados com as questões relacionadas ao ensino e também à aprendizagem de Estatística no âmbito da Escola Básica resolveram juntar-se para elaborá-lo.

Atualmente o AVALE-EB pode ser acessado gratuitamente na internet (em http://avale.iat.educacao.ba.gov.br) e, em contato com o mesmo, o usuário poderá verificar que se configura em muito mais que um software estatístico utilizado para cálculo de medidas, visto que há toda uma filosofia que o norteia, o que pode ser percebido por observações de suas características, como por exemplo, a disponibilização de tutoriais de auxílio aos trabalhos dos professores e estudantes, bem como, as informações detalhadas para o desenvolvimento de cada Sequências de Ensino (SE) direcionadas aos trabalhos envolvendo Estatística e a Probabilidade.

In: M.A. Sorto (Ed.), Advances in statistics education: developments, experiences and assessments. Proceedings of the Satellite conference of the International Association for Statistical Education (IASE), July 2015, Rio de Janeiro, Brazil. 
Diante do que apresentamos até então, temos por objetivo com esta proposta, apresentar as potencialidades de uso do AVALE-EB para o ensino de Estatística na escola, em seus aspectos teóricos e práticos, envolvendo variáveis ordenadas pelo tempo, leitura e interpretação de gráficos, medidas de tendência central e, em especial, as medidas de dispersão, utilizando como instrumento, as etapas da SE Planeta Água.

\section{A RELEVÂNCIA DESTE TRABALHO PARA O ENSINO E FORMAÇÃO DE PROFESSORES}

Conforme apontado, os conteúdos estatísticos são sugeridos de acordo com os Parâmetros Curriculares Nacionais (BRASIL, 1997, 1998) para fazerem parte dos currículos de Matemática da Educação Básica. Em especifico as medidas de variação aparecem indicadas para os trabalhos com estudantes do Ensino Médio, conforme as Orientações Educacionais Suplementares aos Parâmetros Curriculares Nacionais do Ensino Médio, PCN+, (BRASIL, 2002). Percebemos no entanto que as recomendações traduzidas nesses documentos ainda possuem um longo caminho a percorrer no sentido de serem introduzidas de fato no âmbito escolar.

Observamos também, pelo teor das pesquisas realizadas por Godino, Batanero e Flores (1998), Cazorla e Santana (2010), Kataoka et al. (2011) que a inserção de conteúdos estatísticos no âmbito escolar, vem se deparando em alguns obstáculos e dentre eles, formação insuficiente de professores de Matemática para ensinar Estatística e conforme constatamos, entre outros fatores é baseada no uso excessivo de fórmulas, com carência de materiais de apoio didático, incluindo softwares educacionais que auxiliem o entendimento dos conceitos.

É nesse sentido que defendemos a relevância dessa proposta como mais uma disponibilizada com o intuito de auxiliar os trabalhos envolvendo estudantes e professores no contexto em questão, pois, da forma como o AVALE-EB e a SE Planeta Água encontram-se estruturados, por seus objetivos visa contribuir com a diminuição das fragilidades de que tratam os autores citados e por outro lado, o desenvolvimento dessa SE está em harmonia e atendendo as sugestões presentes nos PCN (BRASIL, 1997, 1998, 2002) de abordagens contextualizadas e interdisciplinares.

Por essa proposta, há também a possibilidade de se explorar o tema variabilidade no contexto escolar e, ao discuti-lo, é possível chamar a atenção para a sua importância mostrando de que forma influencia nos processos decisórios.

Garfield e Ben-Zvi (2008) destacam que as dificuldades que os alunos têm em raciocinar sobre o tema variabilidade não residem apenas na aprendizagem do cálculo de medidas formais, mas também, na compreensão de diferentes representações dos conceitos envolvidos nesses cálculos, assim como nas relações destes, com outros conceitos estatísticos. Nesse sentido, a oportunidade que a estrutura da SE Planeta Água traz, permite que sejam abordadas diferentes formas de representações, conforme seja a forma de conduzir adotada.

\section{SEQUÊNCIA DE ENSINO (SE) "PLANETA ÁGUA"}

Está entre as dez presentes no AVALE-EB idealizada para ensino de Estatística com potencial para incentivar atitudes de cidadania. Nela são apresentados alguns procedimentos para tratar os dados de uma conta de consumo de água e, assim sendo, ao mesmo tempo que são trabalhados conceitos estatísticos, procura-se contribuir para a criação de hábitos que favoreçam o uso consciente desse recurso natural tão essencial à existência humana.

Como objetivos associados a esta sequência tem-se: apresentar o uso de conceitos e procedimentos estatístico na análise dos dados contidos na conta de água; apresentar as peculiaridades das variáveis ordenadas no tempo (séries temporais ou séries de tempo) e as implicações didáticas do seu tratamento e discutir diferentes medidas de tendência central e de variabilidade.

Dentre os princípios que a regem, encontra-se o de incentivar o uso de recursos tecnológicos e a participação ativa do sujeito em todas as etapas de uma pesquisa envolvendo a elaboração das questões, identificação das variáveis, coleta e tratamento dos dados e, comunicação dos resultados.

Da forma como está estruturada, permite a investigação da variabilidade nos consumos de água mensais das famílias dos estudantes, ao longo de um ano e, com base na observação de como 
esta ocorre, estabelecer conjecturas sobre os possíveis fatores que contribuem para os gastos apresentados e, simultaneamente, facilita a apropriação em torno dos conteúdos relacionados.

\section{O DESENVOLVIMENTO DA SE PLANETA ÁGUA}

Nessa, como afirmado, as atividades são desenvolvidas nos moldes de uma pesquisa científica e, após uma sensibilização, onde há reflexões sobre a necessidade de se consumir água de forma consciente de acordo com as reais necessidades humanas e segundo as recomendações per capita diárias de 110 litros por pessoas, padronizadas pela Organização das Nações Unidas (ONU), os estudantes são conduzidos a organizar os dados de consumo de suas famílias em um banco construído coletivamente e, com base nos procedimentos referentes a essa fase, elaborar questionamentos para serem respondidos à medida que são desenvolvidas atividades perpassando pelos dois ambientes de aprendizagem: papel e lápis e, computacional.

\section{No ambiente papel e lápis}

As atividades são pensadas para serem desenvolvidas em etapas, sendo que a primeira envolve a análise da conta de consumo mensal da família dos estudantes que, em geral, contém o histórico dos últimos doze meses e que são utilizadas para o preenchimento coletivo do banco de dados (segunda etapa) necessário à realização dos cálculos e de observações, análises e conclusões pelos estudantes. Neste banco de dados também são anotados o número de pessoas que compõe a família. A próxima etapa é destinada à realização de cálculo de medidas resumo e, nesse caso, é solicitado aos estudantes que realizem os cálculos de seus consumos totais anuais, consumo médio familiar mensal, consumo per capita diário, moda, mediana, desvio médio, variância, desvio padrão e coeficiente de variação, utilizando como unidade de medida: metro cúbico e litro exceto para a última medida de variabilidade. As atividades nesse ambiente se encerram com a construção de gráficos de barras e linhas, sendo que em todas elas os estudantes são estimulados a realizarem comentários. A confecção e análise dos gráficos é facilitada pela disponibilização de malhas padronizadas no próprio ambiente AVALE-EB, que inclusive favorece a comparação entre os consumo mensais da família de mais de um estudante por vez pelo fato de serem utilizadas as mesmas escalas na confecção dos mesmos.

\section{No ambiente computacional}

Neste ocorre a potencialização das análises, visto que, após o preenchimento coletivo de um novo banco de dados contendo as mesmas informações do anterior, dessa feita numa versão online, a geração de gráficos e de medidas estatísticas ocorre instantaneamente com uma menor chance de erros e com mínimo de desgastes mentais possíveis.

Para cadastrar-se e introduzir seus dados nesse novo ambiente o estudante precisa acessar o site oficial apresentado anteriormente. Ao adentrar o ambiente, várias informações são disponibilizadas, tais como: objetivos, equipe, etc. Há também informações referentes à Educação Estatística e tutoriais para cada uma das sequências disponíveis de Estatística e Probabilidade, inclusive esta, objeto de nosso enfoque.

Ao final das atividades nos dois ambientes, os estudantes devem retomar aos questionamentos propostos ao início das atividades, visando respondê-los com base em toda construção realizada. Os resultados encontrados devem ser socializados, para o conhecimento de todos e observações acerca da adequação das medidas tomadas para representação dos resultados.

\section{Considerando a variabilidade no contexto dos ambientes apresentados}

Para discutir a variabilidade dos dados nos ambientes apresentados, entre outras formas de intervenção, pode-se solicitar aos estudantes que observem como variam os consumos mensais de água ao longo do ano, quais os valores mínimos e máximos consumidos em litros e em metros cúbicos, a amplitude como a diferença entre esses dois valores. A variação dos consumos mensais em relação ao valor do consumo médio mensal calculado pode ser observada pela análise dos valores encontrados para a variância e desvios padrões. É possível também pela análise dos valores 
dos coeficientes de variação verificar de forma relativa como se deu a variação em torno da média. Com a análise do valor da mediana calculado e dos intervalos interquartílicos abre-se outra possibilidade de investigar a variação dos dados utilizando mais um tipo de representação e, ainda, abre-se o leque de possibilidades de descrevê-la com maior fidedignidade. A ideia de utilizar mais de uma forma de representação da variabilidade é descrita por Garfield e Ben-Zvi (2005) no modelo por eles proposto, como um dos temas a serem explorados dentro da Estatística para o desenvolvimento do entendimento profundo desse conceito.

Nessa mesma linha, a utilização dos recursos gráficos se torna viável, pois permite uma nova visão sobre os dados e para a forma como variam, viabilizando a interpretação com maior rapidez das informações que são disponibilizadas, verificar tendências ou ocorrências sazonais. No caso especifico dessa SE, permite fazer comparações entre perfis de consumos e variabilidade dos mesmos, envolvendo mais de uma família, lembrando que, para esta comparação ocorra de forma adequada, deve ser preservado o mesmo padrão na construções dos gráficos.

\section{CONCLUSÃO}

Em aplicações dessa Sequência de Ensino nos níveis de ensino fundamental, médio e superior, percebemos que os estudantes ficam motivados e envolvidos com os trabalhos, demonstram avançar em termos de aprendizagem acerca dos conteúdos abordados, dentre eles, a variabilidade, que segundo autores é um tema fundamental dentro da Estatística. Verificamos também que a abordagem interdisciplinar e contextualizada faz com que os estudantes estabeleçam significados para os temas em discussão, consolidando a aprendizagem em torno dos conceitos. Consideramos ser esta uma proposta com potencial para contribuir com a lacuna relacionada à carências de materiais de apoio didático ao trabalho do professor e dos estudantes para se juntar a outras existentes que vem sendo apresentadas por pesquisadores nesta área e, ao mesmo tempo, é importante por chamar a atenção dos estudantes para relações de consumos mais conscientes e, nesse caso, a necessidade de preservação da água.

\section{REFERÊNCIAS}

Brasil (1997). Ministério da Educação. Secretaria de Educação Fundamental. Parâmetros Curriculares Nacionais: Matemática. Brasília: Ministério da Educação/Secretaria de Fundamental.

Brasil (2002). PCN+: Ensino Médio - Orientações Educacionais Complementares aos Parâmetros Curriculares Nacionais. Brasília: MEC, 2002.

Cazorla, I. M., \& Kataoka, V. Y. (2010) Ambiente Virtual de Apoio ao Letramento Estatístico AVALE. In: Cazorla, I.; Santana. E.(2010) (Org.) Do Tratamento da Informação ao Letramento Estatístico. Itabuna: Via Litterarum, p. 145 -152.

Gal, I. (2002). Adult's Statistical literacy: Meanings, Components, Responsibilities, International Statistical Review, 70(1), 1-51.

Garfield, J., \& Ben-Zvi, D. (2008). Learning to reason about variability. In J. Garfield \& D. BenZvi (Eds.), Developing Students' Statistical Reasoning: Connecting Research and Teaching Practice. Dordrecht: Springer, p. 201-214.

Garfield, J., \& Ben-Zvi, D. (2005). A framework for teaching and assessing reasoning, about variability. Statistics Education Research Journal, 4(1), 92-99.

Godino, J. D., Batanero, C., \& Flores, P. (1998). El análisis didáctico del conteúdo matemático como recurso en la formación de profesores de matemáticas. Proceedings of the 22nd International Conference for the Psychology of Mathematics Education, Stellenbosch: South Africa.

Kataoka, V.Y. et al. (2011). A Educação Estatística no Ensino Fundamental II em Lavras, Minas Gerais, Brasil: Avaliação e Intervenção. Relime, 14(2). 